\title{
Therapeutic Effect of Black Soybean Flour Intervention on Menopausal Symptoms of Women
}

\author{
Neetu Dobhal* and Rita Singh Raghuvanshi
}

Department of Foods and Nutrition, College of Home Science, G. B. Pant University of Agriculture \& Technology, Pantnagar (263145), District- Udham Singh Nagar, Uttarakhand, India

*Corresponding author

\section{A B S T R A C T}

Keywords

Menopause,

Postmenopausal

women, Black

soybean,

Vasomotor domain,

Vaginal health

domain

\section{Article Info}

Accepted:

22 October 2019

Available Online:

10 November 2019
The present research was undertaken to evaluate the effect of black soybean flour intervention on menopausal symptoms of postmenopausal women. It was an experimental design with pre and post observations including 46 postmenopausal women of 45-55 years. The women were selected as per inclusion criteria and randomly divided into 2 groups. The women in Experimental group A and B received $50 \mathrm{~g} /$ day of raw and germinated black soybean flour, respectively, for consecutive 90 days. Information regarding menopause was collected at the beginning of intervention period and 90 days after initiation of intervention using Menopause-SpecificQuality of Life Questionnaire. The dietary intervention significantly improved the symptoms related to vasomotor, psychological and physical domain but didn't have any significant effect on the symptoms related to sexual and vaginal health domains. The study concludes that incorporation of black soybean flour in daily diet can improve complications of postmenopausal symptoms and improve the quality of life of women.

\section{Introduction}

Human life encompasses several developmental and growth transitions like adolescence, adulthood and menopause, some of which, especially menopause, are usually not only biological but also involve social and psychological changes. Menopause is a natural transition experienced by every woman characterized by falling levels of estrogen and progesterone hormones, which involves loss of the reproductive function. WHO (1981) has defined menopause as "the permanent cessation of menstruation in a woman due to loss of ovarian follicular activity". 
The three phases of menopause i.e. premenopause, perimenopause and postmenopause comprise about $1 / 2-1 / 3^{\text {rd }}$ of a woman's life since the life expectancy of women in developed countries is approximately 84.3 years with the average age for menopause as 50-52 years (Abdollahi et al., 2013). As per Indian Menopause Society, the average age of Indian menopausal women is 47.5 years which is lower than the average age of menopause in the western world i.e. 51 years (Pal et al., 2013).

When women reach menopause, hormonal shifts makes them to face difficulties ranging from symptoms to complications. Menopause may be associated with vasomotor symptoms, psychological symptoms, physical symptoms, vaginal health symptoms, sexual symptoms and many more, which can significantly disrupt their daily activities and their sense of well-being (Abedzadeh et al., 2012). The long-term complications of menopause may include osteoporosis (Betts et al., 2017), cancer (Wu et al., 2008), CVDs (Zhoua et al., 2015), urogenital problems (WHO, 1981) and diabetes mellitus (Ko, 2014) etc.

Women adopt a wide range of coping strategies to manage menopausal symptoms which may include Psychological, social, informational, practical and organisational strategies and changing health behaviours (exercise, sleep, diet) (Grifith et al., 2013). Hormone replacement therapy is an effective treatment available for the relief of menopausal symptoms. However, it is reported that women receiving HRT are likely to have several side effects including increased risk for breast cancer and endometrial cancer, osteoporosis, heart disease, stroke and Alzheimer's disease (Darke, 1996). Many women use plant-based alternatives to manage menopausal symptoms including foods or herbal products containing estrogens.

Soybean and its products being rich in isoflavones (phytoestrogen) have the potential to provide an exogenous source of estrogen for women after menopause and thus proposed as an alternative to conventional hormone therapy (Setchell, 2001). Black soybean (Glycine max (L.) Merrill), locally known as Bhatt/Bhatmash, is grown in 5734 hectare area of Uttarakhand with the yield and productivity of 5636t and 9.82q/ha, respectively (Hipparagi et al., 2017).

Various studies have reported the antioxidant, antitumor, hepatoprotective, hypolipidemic and estrogenic activity of black soybean along with its role in preventing benign prostrate hypertrophy, prostrate cancers and ovarian cancers (Shah, 2006; Ganeshan and Xu, 2017; Chen et al., 2017).

Despite of having numerous health benefits, black soybean is consumed on a very limited scale in India due to lack of its nutritional and therapeutic importance. Therefore, the present study was undertaken to assess the therapeutic role of processed black soybean flour in ameliorating the menopausal symptoms among postmenopausal women.

\section{Materials and Methods}

\section{Locale}

The intervention study was carried in district Udham Singh Nagar of Uttarakhand in the year 2018.

\section{Material procurement}

Black soybean (VL-63 variety) was procured from Tarai Development Corporation (TDC), Haldi, District U.S. Nagar (Uttarakhand). The seeds of black soybean were cleaned manually to remove foreign materials (dust, dirt, grit and 
other impurities), broken and immature soybeans.

\section{Flour development}

Two types of flour were developed from black soybean i.e. raw and germinated black soybean flour. For preparation of germinated flour, black soybean grains were washed in clean water followed by overnight soaking and draining. Next day, soaked grains were kept for germination for next 72 hours at $32 \pm 2{ }^{0} \mathrm{C}$ in incubator. Germinated grains were oven-dried at $65 \pm 2{ }^{\circ} \mathrm{C}$ till completely dried, followed by grinding into flour, sieving through 60 mesh sieve and storing the flour in dry and air tight containers for further use.

\section{Subject selection}

\section{Inclusion criteria}

Women within age group of 45-55 years with absence of menses for at least 12 months but not more than 5 years, complaining of hot flushes and willing to participate in present research were included in the study.

\section{Exclusion criteria}

Women receiving any hormone-replacement therapy for treatment of menopausal symptoms and with history of any degenerative diseases such as myocardial infarction, stroke, congestive heart failure, hepatitis, malignant disease of breast or any suspected estrogen-dependent tumours and endometrial carcinoma were excluded.

Women with known allergy or hypersensitivity to soybean and with habit of drinking alcohol and cigarette smoking were also excluded.

\section{Sample size estimation}

Sample size for the present study was estimated using the formula given by Dhulkhed et al., 2008.

$\mathrm{n}=\frac{2(\mathrm{SD})^{2}\left(\mathrm{Z}_{\alpha / 2}+\mathrm{Z}_{\beta}\right)^{2}}{\mathrm{~d}^{2}}$

where $\mathrm{Z}_{\alpha / 2}$ \{Probability of Type I (Alpha) error $\}=1.96(95 \%$ power $)$

$\mathrm{Z}_{\beta}\{$ Probability of Type II (Beta) error $\}=$ 0.842 (80\% precision)

$\mathrm{SD}=$ Standard deviation,

$\mathrm{d}=$ difference of means

The required sample was found to be 46 . For selection of subjects, door to door survey was conducted in the localities of district Udham Singh Nagar, Uttarakhand. A list of total 157 menopausal women was prepared and they were assessed for their eligibility in the study. Out of 157, 27 women were excluded as they didn't meet the inclusion criteria. Among remaining 130 menopausal women, 50 women were randomly selected using random number tables.

\section{Ethical considerations}

Subjects were explained about the nature and purpose of study and a fully informed written consent was taken from each subject. A formal approval was taken from the University Ethics Committee for Human Research (UECHR) G.B. Pant University of Agriculture and Technology, Pantnagar, Uttarakhand.

\section{Study tool}

The subjects were interviewed for the sociodemographic information such as name, age, religion, social category, marital status, education, occupation, family type and family size etc using a structured interview schedule. Anthropometric measurements of the subjects (height, weight, mid-upper-armcircumference, waist and hip circumference) 
were taken as per methods described by Jelliffe (1966) using standard equipments. BMI was calculated and subjects were categorized into different categories of nutritional status as per the classification given by WHO (2004).Value of 18.5 was taken as cut-off point of undernourishment for the subjects, while more than equal to 23.0 was considered as an indicator of overweight. Waist-to-hip ratio was calculated from waist and hip circumference measurements. A waist to hip circumference greater than 0.85 in women indicated abdominal adiposity (WHO, 2002).

Information on menopausal symptoms was collected using "Menopause-Specific Quality of Life Questionnaire" developed by Primary Care Research Unit, University of Toronto (Hilditch and Lewis, 1996). The entire questionnaire was divided into five domains i.e. vasomotor, psychosocial, physical, vaginal health and sexual domain. Under each domain, questions related to presence and severity of menopausal symptoms was asked. For each question, subjects had to answer on the basis of problem experienced by them in the last one month.

To ensure the validity of the interview schedule, the preliminary schedule was pilottested on 10 menopausal women in the age group of 45-55 years. Thereafter necessary modifications were incorporated and modified interview schedule was used in the present study. The subjects included in the pilot study were not included in the final study. The scoring of each symptom was done using "Likert scoring method" (Kumar et al., 2016) in which score increased point by point with increasing severity of perceived symptoms from 0 (No symptom) to 4 (1-mild, 2moderate, 3-severe, 4-very severe) in each of the 30 symptom. Mean scores for each symptom in a group and mean score for specific domains were calculated.
Black soybean flour was taken as a product for supplementation in the present study and subjects were instructed to consume 50g black soybean flour per day in the form of chapatti in any of their meals i.e. breakfast, lunch or dinner.

\section{Study design}

Subjects were randomly allocated into two groups - Experimental group A and B. Each group consisted of 25 subjects, for whom, the intervention programme was conducted for a period of 90 days. Experimental group A received raw black soybean flour whereas group B received germinated black soybean flour (50g in well sealed zip-lock pouch/day) for 90 days. Regular monitoring of dietary intervention was done either through home visit or telephone call.

All the 50 subjects were examined for menopausal symptoms on zero day i.e. before the initiation of the study. This baseline data served as control for the subjects in the study. It was followed by supplementation period of ninety days.

Four subjects quit in-between the study, due to personal reasons and finally the dietary intervention was completed by only 46 subjects. On completion of ninetieth day, all the 46 subjects were again examined for menopausal symptoms after intervention (Figure 1).

\section{Statistical analysis}

The data on all the menopausal symptoms was analyzed statistically (Snedecor and Cochran, 1967). Paired t-test was applied between the 'baseline' and 'after intervention' values of a parameter of individual subjects. Two-sample t-test was used to find out the significance of difference between the two experimental groups for various parameters. 


\section{Results and Discussion}

\section{Characteristics of the study population}

The study included 46 postmenopausal women aged 45-55 years. Majority of the subjects belonged to the Hindu religion $(93.48 \%)$ and were married $(80.43 \%)$. The data on education of subjects (Table 1) revealed that majority i.e. $43.48 \%$ subjects were educated up to post graduation and above, followed by 15.21 and $10.87 \%$ subjects who were educated up to primary and graduation levels, respectively. More than half i.e. $56.52 \%$ subjects were housewives who were not involved in income generation outside. Rest about $43.48 \%$ subjects was employed.

Majority i.e. $65.22 \%$ subjects belonged to nuclear families. More than $72 \%$ subjects had small family size having 1-4 members, followed by $21.74 \%$ of families having 5-8 members. Per capita income of the study population ranged from Rs. 2500-81250 per month. The factors responsible for higher per capita income in the present study might be the more number of nuclear families with majority of subjects having small family size.

\section{Anthropometric measurements of study population}

Anthropometric details of study population are presented in table 2. The data showed that height and weight of subjects varied from $137.80-161.30 \mathrm{~cm}$ and $43.60-104.40 \mathrm{~kg}$ with the mean height of $151.80 \pm 5.64 \mathrm{~cm}$ and mean weight of $63.81 \pm 9.80 \mathrm{~kg}$, respectively. The mean BMI of subjects was $27.70 \pm 4.08 \mathrm{~kg} / \mathrm{m}^{2}$. Distribution of subjects on the basis of BMI data showed that majority of the subjects were pre-obese $(58.7 \%)$, followed by $17.39 \%$ women categorized as obese grade I (Figure 3). The mean MUAC, waist circumference and hip circumference of the subjects in the present study was $30.13 \pm 3.21 \mathrm{~cm}$, $98.45 \pm 10.13 \mathrm{~cm} 103.64 \pm 8.38 \mathrm{~cm}$, respectively. In the present study, WHR of subjects varied from $0.83-1.24$ with $86.96 \%$ subjects having abdominal obesity.

\section{Mean age at menopause}

The findings of the present study revealed that mean age of menopause was $48.42 \pm 2.77$ and $49.13 \pm 2.85$ years for subjects of groups $\mathrm{A}$ and $\mathrm{B}$, respectively.

Impact of dietary intervention of black soybean flour on menopausal symptoms

\section{Vasomotor domain}

Figure 2 represents severity of vasomotor domain symptoms of the subjects which included hot flushes and nocturnal sweating. Data on intensity of hot flushes showed that before dietary intervention 27.3 and $29.2 \%$ subjects of groups A and B experienced 'very severe' hot flushes which reduced to 4.6 and $12.5 \%$, respectively, after intervention. Nocturnal sweating was reported only by $36.96 \%$ subjects of the study.

Severe intensity of nocturnal sweating was reported by 40.9 and $25 \%$ subjects before intervention which reduced to 27.3 and $16.67 \%$, respectively. On comparison of mean scores (Table 3) at baseline and after intervention, significant $(\mathrm{p} \leq 0.05)$ decreases of 26.95 and $34.61 \%$ were observed in groups $\mathrm{A}$ and $\mathrm{B}$, respectively. The mean scores of vasomotor symptoms reported by subjects of both the groups were found non-significantly $(\mathrm{p} \leq 0.05)$ different from each other.

\section{Psychological domain}

The findings of the study (Table 4) showed that decrease in work performance, poor memory, lack of drive for work and 
anxiousness were the most common problems reported by subjects under psychological domain. The overall mean score of psychological domain at baseline showed significant $(\mathrm{p} \leq 0.05)$ reductions of 23.65 and $26.63 \%$ in group A and B, respectively after intervention. A non-significant $(\mathrm{p} \leq 0.05)$ difference was observed in the overall mean score of psychological domain in both groups. None of the subjects reported "very severe" intensity of symptom under psychological domain.

\section{Physical domain}

In the present study, the most commonly observed physical domain symptoms were feeling of tiredness $(82.6 \%$ subjects $)$, decrease in physical strength (89.1\%), muscles/joints ache $(80.4 \%)$, dry skin $(82.6 \%)$ and bladder inconsistence $(67.4 \%)$ (Table 5). The overall mean score of physical domain in group A and group B at baseline showed significant $(\mathrm{p} \leq 0.05)$ reductions of 43.62 and $42.85 \%$ after the dietary interventions of raw and germinated black soybean flours, respectively. A nonsignificant $(\mathrm{p} \leq 0.05)$ difference was observed in the mean scores of physical domain of groups A and B. None of the subjects reported "very severe" intensity of symptom under physical domain.

Postmenopausal women have an increased tendency for gaining weight. In the present study, data on the weight gain after menopause showed a wide range of 0 to $15 \mathrm{~kg}$. About 46 and $26 \%$ subjects reported mild $(1-5 \mathrm{~kg})$ and moderate $(5-10 \mathrm{~kg})$ weight gain after menopause while $26 \%$ subjects didn't report any weight gain after menopause.

\section{Vaginal health domain and sexual domain}

The vaginal health domain included symptoms like vaginal itching, vaginal discharge, vaginal pain or bleeding during sex. The overall mean scores of vaginal health symptoms viz vaginal itching and vaginal discharge decreased nonsignificantly $(p \leq 0.05)$ from 0.36 to 0.32 in group $\mathrm{A}$ and from 0.29 to 0.25 in group B, respectively, after intervention (Table 6). None of the subjects complained about the vaginal bleeding in the present study. Also, the mean scores of vaginal health symptoms reported by subjects of two groups were found to be non-significantly $(\mathrm{p} \leq 0.05)$ different from each other.

The sexual domain symptoms included decreased sexual desire, avoiding intimacy with husband and satisfaction after sex. The findings of the present study showed no significant $(p \leq 0.05)$ improvement in sexual problems. An increase of $23.91 \%$ in percentage of subjects with loss of libido (decrease in sexual desire) was observed after the dietary intervention (Table 7). The findings concluded that the dietary intervention of raw and germinated black soybean flour didn't have any positive role in improving sexual problems related with postmenopausal stage.

The data on overall changes in the severity of menopausal symptoms perceived by the subjects showed maximum improvement in symptoms of physical domain, followed by the psychological domain, vaginal health and vasomotor domain as 95.65, 80.43, 76.09 and $71.74 \%$ subjects, respectively, reported positive change in menopausal symptoms. Negative change was not at all reported by the subjects.

The present study investigated the prevalence of menopausal symptoms in postmenopausal women aged 45-55years of Uttarakhand state. Under anthropometric measurements, mean height of subjects in the present study was found lower than the reference height of $161 \mathrm{~cm}$ (ICMR, 2010) for Indian women. Dobhal and Raghuvanshi (2008) reported the 
mean height and weight of adult women of Uttarakhand as $154 \mathrm{~cm}$ and $50.76 \mathrm{~kg}$. Based on BMI classification, Patel et al., (2016) and Sen and Verma (2016) reported the prevalence of overweight/obesity in 61 and 44\% women, respectively. WHR indicates the prevalence of visceral fat i.e. the dangerous internal fat coating the organs. Patricia et al., (2011) and Sen and Verma (2016) reported the mean WHR of menopausal women as $0.81 \pm 0.08$ and $0.90 \pm 0.1$.

The mean age at menopause in the present study was found to be $48.79 \pm 2.80$ years. This is consistent with the study results of Randhawa and Sindhu (2014) and Madhukumar et al., (2012) in different parts of India as 48.86 \pm 2.12 and 49.33years, respectively. Various studies have reported the age of menopause in women of different countries varying from 44.7 years (Mansour et al., 2014) to 50.9years (Meschia et al., 2000). The wide variation in the age of menopause in women may probably be because of regional, community and ethnic variations, genetic and environment factors.

Hot flushes and nocturnal sweating are the classical symptoms of menopause. In the present study, all the subjects were experiencing hot flushes and $63.04 \%$ reported nocturnal sweating. Hot flush is described as a sensation of heat in the upper body (face, neck, chest and arms) often followed by sweating and chills, and may be accompanied by palpitation, fatigue, irritability, anxiety, and panic (Zhang et al., 2009). Hot flushes occurrence might be due to the narrowing of the inter threshold zone (within the hypothalamic thermoregulatory zone) during menopause, which is defined as the threshold between sweating and shivering (Stearns et al., 2002). Another mechanism for the hot flush might be the result of elevated body temperature leading to cutaneous vasodilatation, leading to flushing or sweating in association with a decrease in temperature and chills (Goodman et al., 2011).

Various studies have reported the percentage of postmenopausal women experiencing hot flushes as 44.3 (Gyawali et al., 2016), 60 (Karmarkar et al., 2018) and 70.6\% (Masjoudi et al., 2017). The beneficial effect of dietary soybean products in reducing hot flushes in menopausal women has been reported by Salvador et al., (2016). A longitudinal, multicentric, multiethnic, community study conducted by Green et al., (2009) included menopausal women from different countries. The results showed that the prevalence of combined hot flushes and night sweating was lowest among women of Japanese (18\%) origin, while increasing among Chinese (21\%), Caucasian (31\%), Hispanic (35\%), and African Americans (46\%). It was hypothesized that diet plays a role in the type and severity of menopausal symptoms. It was found that a diet high in phytoestrogens protects against vasomotor symptoms. Soybean is a rich source of phytoestrogens. A typical Japanese diet contains high amounts of soybean, and this might be associated with a decrease in vasomotor symptoms.

In the current study, the most common psychological symptoms found were lack of drive to do work (80.4\%), decrease in wok performance (78.3\%), anxiousness (73.9\%) and poor memory (73.9\%). A study done by Bairy et al., (2009) showed high prevalence of aching in muscles and joints $(67.7 \%)$, feeling tired $(64.8 \%)$, poor memory $(60.5 \%)$, lower backache $(58.8 \%)$, feeling bloated $(55.1 \%)$, and difficulty in sleeping $(51.7 \%)$ among the postmenopausal respondents. Lu et al., (2007) conducted a cross-sectional survey in Australia among women aged 45-65 years and reported "feeling of tiredness" $(86 \%)$ and "aching in muscles and joints" (85\%) as most frequent symptoms. 
Table.1 General profile of the subjects

\begin{tabular}{|c|c|c|c|}
\hline & & & $\mathrm{N}=46)$ \\
\hline Characteristic & per cent & Characteristic & per cent \\
\hline \multicolumn{2}{|c|}{ Age (Years) } & \multicolumn{2}{|l|}{ Religion } \\
\hline $45-50$ & 36.96 & Hindu & 93.48 \\
\hline $50-55$ & 63.04 & Muslim & 6.52 \\
\hline \multicolumn{2}{|c|}{ Occupation of the subject } & \multicolumn{2}{|c|}{ Marital status } \\
\hline Employed & 43.48 & Married & 80.43 \\
\hline Unemployed & 56.52 & Widow & 19.57 \\
\hline Family type & & Family size & \\
\hline Nuclear & 65.22 & Small (1-4 members) & 73.91 \\
\hline Joint & 2.17 & Medium (5-8 members) & 21.74 \\
\hline Extended & 32.61 & Large (>8 members) & 4.35 \\
\hline \multicolumn{2}{|c|}{ Education } & \multicolumn{2}{|c|}{ Per capita monthly income (Rs.) } \\
\hline Illiterate & 8.70 & $1000-10000$ & 34.78 \\
\hline Primary & 15.21 & $10000-20000$ & 30.43 \\
\hline Junior High School & 4.34 & 20000-30000 & 15.22 \\
\hline High School & 8.70 & $30000-40000$ & 10.87 \\
\hline Intermediate & 8.70 & $40000-50000$ & 4.35 \\
\hline Graduation & 10.87 & $50000-60000$ & 2.17 \\
\hline $\begin{array}{c}\text { Post graduation and } \\
\text { above }\end{array}$ & 43.48 & $>80000$ & 2.17 \\
\hline
\end{tabular}

Table.2 Anthropometric parameters of subjects

\begin{tabular}{|c|c|c|}
\hline Parameters & Mean value & Range \\
\hline Height $(\mathbf{c m})$ & $151.80 \pm 5.64$ & $137.80-161.30$ \\
\hline Weight $(\mathbf{k g})$ & $63.81 \pm 9.80$ & $43.60-104.40$ \\
\hline BMI $\left(\mathbf{k g} \mathbf{m}^{\mathbf{2}}\right)$ & $27.70 \pm 4.08$ & $20.04-44.60$ \\
\hline $\begin{array}{c}\text { Waist circumference } \\
(\mathbf{c m})\end{array}$ & $98.45 \pm 10.13$ & $73.70-122.50$ \\
\hline Hip circumference (cm) & $103.64 \pm 8.38$ & $77.20-131.30$ \\
\hline WHR & $0.95 \pm 0.07$ & $0.83-1.24$ \\
\hline MUAC (cm) & $30.13 \pm 3.21$ & $22.40-41.30$ \\
\hline
\end{tabular}

Values represent mean \pm SE 
Table.3 Mean scores of menopausal symptoms of the subjects before and after the dietary intervention

\begin{tabular}{|c|c|c|c|c|c|}
\hline Symptoms & Groups & Baseline & Final & \% Change & $\begin{array}{c}\text { Paired } \\
\text { t-value }\end{array}$ \\
\hline \multirow{2}{*}{ Vasomotor domain } & $\mathrm{A}$ & $4.86 \pm 2.27$ & $3.55 \pm 1.95$ & 26.95 & $6.22^{*}$ \\
\cline { 2 - 6 } & $\mathrm{B}$ & $4.71 \pm 2.33$ & $3.08 \pm 1.74$ & 34.61 & $5.42^{*}$ \\
\cline { 2 - 6 } & $\mathbf{t}_{\mathrm{AB}}$-value & $0.23^{\mathrm{NS}}$ & $0.85^{\mathrm{NS}}$ & & \\
\hline \multirow{2}{*}{ Psychological domain } & $\mathrm{A}$ & $9.64 \pm 3.82$ & $7.36 \pm 2.48$ & 23.65 & $5.59^{*}$ \\
\cline { 2 - 6 } & $\mathrm{B}$ & $8.75 \pm 4.94$ & $6.42 \pm 3.59$ & 26.63 & $5.93^{*}$ \\
\cline { 2 - 6 } & $\mathbf{t}_{\mathbf{A B}}$-value & $0.68^{\mathrm{NS}}$ & $1.05^{\mathrm{NS}}$ & & \\
\hline \multirow{2}{*}{ Physical domain } & $\mathrm{A}$ & $11.05 \pm 5.67$ & $6.23 \pm 3.41$ & 43.62 & $7.87^{*}$ \\
\cline { 2 - 6 } & $\mathrm{B}$ & $11.88 \pm 5.33$ & $6.79 \pm 3.67$ & 42.85 & $9.11^{*}$ \\
\cline { 2 - 6 } & $\mathbf{t}_{\mathbf{A B}}$-value & $0.51^{\mathrm{NS}}$ & $0.54^{\mathrm{NS}}$ & & $1.37^{\mathrm{NS}}$ \\
\hline \multirow{2}{*}{ Vaginal domain } & $\mathrm{A}$ & $0.41 \pm 0.16$ & $0.37 \pm 0.12$ & 31.71 & $1.36^{\mathrm{NS}}$ \\
\cline { 2 - 6 } & $\mathrm{B}$ & $0.54 \pm 0.20$ & $0.49 \pm 0.13$ & 27.78 & \\
\cline { 2 - 6 } & $\mathbf{t}_{\mathbf{A B}}$-value & $0.49^{\mathrm{NS}}$ & $0.80^{\mathrm{NS}}$ & & \\
\hline
\end{tabular}

Group A= Intervened with raw black soybean flour (22 subjects), Group B= Intervened with germinated black soybean flour (24 subjects), - Values not reported, $\mathrm{t}_{\mathrm{AB}}$-value shows the comparison between group $\mathrm{A}$ and group $\mathrm{B}, *$ shows significant difference between values at $5 \%$ level of significance, NS: non-significant

Table.4 Effect of dietary intervention on menopausal symptoms of psychological domain

\begin{tabular}{|c|c|c|c|c|c|c|c|c|c|c|c|}
\hline \multirow[t]{2}{*}{ Symptoms } & \multirow[b]{2}{*}{ Groups } & \multicolumn{5}{|c|}{ Before intervention (\%) } & \multicolumn{5}{|c|}{ After intervention (\%) } \\
\hline & & 3 & 2 & 1 & 0 & Mean & 3 & 2 & 1 & 0 & Mean \\
\hline \multirow[t]{2}{*}{ Depression } & $\mathbf{A}$ & 4.6 & 9.1 & 45.5 & 40.9 & 0.77 & 4.6 & 0 & 54.5 & 40.9 & 0.68 \\
\hline & B & - & 25 & 29.2 & 45.8 & 0.79 & - & 16.7 & 37.5 & 45.8 & 0.71 \\
\hline \multirow{2}{*}{$\begin{array}{c}\text { Lack of drive for } \\
\text { work }\end{array}$} & $\mathbf{A}$ & 13.6 & 45.5 & 22.7 & 18.2 & 1.18 & - & 31.8 & 50 & 18.2 & 1.14 \\
\hline & B & 8.3 & 45.8 & 25 & 20.8 & 1.42 & - & 20.8 & 58.3 & 20.8 & 1.00 \\
\hline \multirow{2}{*}{$\begin{array}{l}\text { Feeling of wanting to } \\
\text { be alone }\end{array}$} & $\mathbf{A}$ & - & 4.55 & 27.3 & 68.2 & 0.36 & - & 0 & 31.8 & 68.2 & 0.32 \\
\hline & B & - & 4.2 & 25 & 70.8 & 0.33 & - & 0 & 29.2 & 70.8 & 0.29 \\
\hline \multirow{2}{*}{$\begin{array}{c}\text { Dissatisfaction with } \\
\text { personal life }\end{array}$} & A & 4.6 & 4.6 & 13.6 & 77.3 & 0.36 & - & 4.6 & 13.6 & 81.8 & 0.23 \\
\hline & B & - & 16.7 & 4.2 & 79.2 & 0.38 & - & 8.3 & 12.5 & 79.2 & 0.29 \\
\hline \multirow[t]{2}{*}{ Anxiousness } & $\mathbf{A}$ & - & 31.8 & 50 & 18.2 & 1.14 & - & 13.6 & 59.1 & 27.3 & 0.86 \\
\hline & B & 4.2 & 25 & 37.5 & 33.3 & 1.00 & - & 12.5 & 58.3 & 29.2 & 0.83 \\
\hline \multirow[t]{2}{*}{ Impatience } & $\mathbf{A}$ & - & 31.8 & 22.7 & 45.5 & 0.86 & - & 13.6 & 40.9 & 45.5 & 0.68 \\
\hline & B & - & 16.7 & 12.5 & 70.8 & 0.46 & - & 4.2 & 25 & 70.8 & 0.33 \\
\hline \multirow{2}{*}{$\begin{array}{l}\text { Decrease in work } \\
\text { performance }\end{array}$} & $\mathbf{A}$ & 18.2 & 50 & 9.1 & 22.7 & 1.64 & - & 36.4 & 40.9 & 22.7 & 1.14 \\
\hline & B & 4.2 & 50 & 25 & 20.8 & 1.38 & - & 20.8 & 58.3 & 20.8 & 1.00 \\
\hline \multirow{2}{*}{$\begin{array}{l}\text { Experiencing poor } \\
\text { memory }\end{array}$} & $\mathbf{A}$ & 4.6 & 45.5 & 27.3 & 22.7 & 1.32 & - & 31.8 & 50 & 18.2 & 1.14 \\
\hline & B & 4.2 & 33.3 & 33.3 & 29.2 & 1.13 & - & 29.2 & 50 & 20.8 & 1.08 \\
\hline \multirow{2}{*}{$\begin{array}{c}\text { Difficulty in falling } \\
\text { asleep }\end{array}$} & A & 13.6 & 31.8 & 9.1 & 45.5 & 1.14 & - & 13.6 & 36.4 & 50 & 0.64 \\
\hline & B & 12.5 & 25 & 4.2 & 58.3 & 0.92 & - & 16.7 & 25 & 58.3 & 0.58 \\
\hline \multirow{2}{*}{$\begin{array}{c}\text { Difficulty in sleeping } \\
\text { through }\end{array}$} & $\mathbf{A}$ & 22.7 & 22.7 & 9.1 & 45.5 & 1.23 & - & - & 31.8 & 68.2 & 0.32 \\
\hline & B & 16.7 & 20.8 & 4.2 & 58.3 & 0.96 & - & - & 33.3 & 66.7 & 0.33 \\
\hline
\end{tabular}

3=Severe, $2=$ Moderate, $1=$ Mild, $0=$ None, Group $\mathrm{A}=$ Intervened with raw black soybean flour (22 subjects), Group $\mathrm{B}=$ Intervened with germinated black soybean flour (24 subjects), - Values not reported 
Table.5 Effect of dietary intervention on menopausal symptoms of physical domain

\begin{tabular}{|c|c|c|c|c|c|c|c|c|c|c|c|}
\hline \multirow[t]{2}{*}{ Symptoms } & \multirow{2}{*}{$\begin{array}{l}\text { Group } \\
\mathbf{s}\end{array}$} & \multicolumn{5}{|c|}{ Before intervention (\%) } & \multicolumn{5}{|c|}{ After intervention (\%) } \\
\hline & & 3 & 2 & 1 & 0 & Mean & 3 & 2 & 1 & 0 & Mean \\
\hline \multirow[t]{2}{*}{ Muscles/joints ache } & A & 36.4 & 22.7 & 13.6 & 27.3 & 1.68 & 9.1 & 45.5 & 18.2 & 27.3 & 1.36 \\
\hline & B & 45.8 & 29.2 & 12.5 & 12.5 & 2.08 & 25 & 37.5 & 25 & 12.5 & 1.75 \\
\hline \multirow[t]{2}{*}{ Tiredness } & $\mathbf{A}$ & 40.9 & 31.8 & 4.5 & 22.7 & 1.91 & - & 4.6 & 45.5 & 50 & 0.55 \\
\hline & B & 41.7 & 33.3 & 12.5 & 12.5 & 2.04 & - & 4.2 & 58.3 & 37.5 & 0.67 \\
\hline \multirow[t]{2}{*}{ Head/ neck ache } & $\mathbf{A}$ & 31.8 & 18.2 & 18.2 & 31.8 & 1.50 & 9.1 & 31.8 & 27.3 & 31.8 & 1.18 \\
\hline & B & 16.7 & 33.3 & 16.7 & 33.3 & 1.33 & 8.3 & 29.2 & 25 & 37.5 & 1.08 \\
\hline \multirow[t]{2}{*}{ Flatulence } & $\mathbf{A}$ & 4.5 & 13.6 & 59.1 & 22.7 & 1.00 & - & 9.1 & 72.7 & 18.2 & 0.91 \\
\hline & B & - & 25 & 41.7 & 33.3 & 0.75 & - & 12.5 & 50 & 37.5 & 0.75 \\
\hline \multirow{2}{*}{$\begin{array}{l}\text { Decrease in physical } \\
\text { stamina }\end{array}$} & $\mathbf{A}$ & 22.7 & 45.5 & 22.7 & 9.1 & 1.82 & - & 4.6 & 31.8 & 63.7 & 0.41 \\
\hline & B & 12.5 & 58.3 & 16.7 & 12.5 & 1.71 & - & - & 50 & 50 & 0.5 \\
\hline \multirow[t]{2}{*}{ Dry skin } & $\mathbf{A}$ & 13.6 & 50 & 13.6 & 22.7 & 1.55 & - & 9.1 & 50 & 40.9 & 0.68 \\
\hline & B & 8.3 & 37.5 & 41.7 & 12.5 & 1.42 & - & 8.33 & 50 & 41.7 & 0.67 \\
\hline \multirow[t]{2}{*}{ Increased facial hair } & $\mathbf{A}$ & - & 13.6 & - & 86.4 & 0.27 & - & 13.6 & - & 86.4 & 0.27 \\
\hline & B & - & 12.5 & - & 87.5 & 0.25 & - & 12.5 & - & 87.5 & 0.25 \\
\hline \multirow[t]{2}{*}{ Pain during urination } & $\mathbf{A}$ & - & 13.6 & 4.5 & 81.8 & 0.32 & - & - & 13.6 & 86.4 & 0.14 \\
\hline & B & - & 8.3 & 12.5 & 79.2 & 0.29 & - & - & 20.8 & 79.2 & 0.21 \\
\hline \multirow{2}{*}{$\begin{array}{c}\text { Increased need to } \\
\text { urinate }\end{array}$} & $\mathbf{A}$ & - & 9.1 & 27.3 & 63.6 & 0.45 & - & 9.1 & 18.2 & 72.7 & 0.36 \\
\hline & B & - & 12.5 & 16.7 & 70.8 & 0.42 & - & 12.5 & - & 87.5 & 0.25 \\
\hline \multirow[t]{2}{*}{ Bladder inconsistence } & $\mathbf{A}$ & 18.2 & 18.2 & 13.6 & 50 & 1.05 & - & 4.6 & 40.9 & 54.6 & 0.50 \\
\hline & B & 8.3 & 20.8 & 4.2 & 66.7 & 0.71 & - & 8.3 & 25 & 66.7 & 0.42 \\
\hline
\end{tabular}

3=Severe, $2=$ Moderate, $1=$ Mild, $0=$ None, Group A= Intervened with raw black soybean flour (22 subjects), Group $\mathrm{B}=$ Intervened with germinated black soybean flour (24 subjects), - Values not reported

Table.6 Effect of dietary intervention on menopausal symptoms of vaginal health domain

\begin{tabular}{|c|c|c|c|c|c|}
\hline \multirow[t]{2}{*}{ Symptoms } & \multirow[t]{2}{*}{ Severity } & \multicolumn{2}{|c|}{ Group A } & \multicolumn{2}{|c|}{ Group B } \\
\hline & & Before int. & After int. & Before int. & After int. \\
\hline \multirow[t]{5}{*}{ Vaginal itching } & Severe (3) & - & - & - & - \\
\hline & Moderate (2) & 13.6 & 9.1 & 8.3 & 4.2 \\
\hline & Mild (1) & 9.1 & 13.5 & 12.5 & 16.7 \\
\hline & Nil (0) & 77.3 & 77.3 & 79.2 & 79.2 \\
\hline & Mean & 0.36 & 0.32 & 0.29 & 0.25 \\
\hline \multirow[t]{5}{*}{ Vaginal discharge } & Severe (3) & - & - & 4.2 & - \\
\hline & Moderate (2) & 9.1 & 4.5 & 4.2 & 8.3 \\
\hline & Mild (1) & - & 4.5 & 12.5 & 12.5 \\
\hline & Nil (0) & 90.9 & 90.9 & 79.2 & 79.2 \\
\hline & Mean & 0.18 & 0.14 & 0.33 & 0.29 \\
\hline \multirow{4}{*}{$\begin{array}{l}\text { Vaginal pain during } \\
\text { intercourse }\end{array}$} & Yes & 9.1 & 9.1 & 16.7 & 16.7 \\
\hline & No & 63.6 & 68.2 & 54.2 & 54.2 \\
\hline & No comment & 9.1 & 4.6 & 8.3 & 8.3 \\
\hline & Not applicable & 18.2 & 18.2 & 20.8 & 20.8 \\
\hline \multirow{4}{*}{$\begin{array}{l}\text { Vaginal bleeding during } \\
\text { intercourse }\end{array}$} & Yes & - & - & - & - \\
\hline & No & 72.7 & 72.7 & 70.8 & 70.8 \\
\hline & No comment & 9.1 & 9.1 & 8.3 & 8.3 \\
\hline & Not applicable & 18.2 & 18.2 & 20.8 & 20.8 \\
\hline
\end{tabular}

Group A= Intervened with raw black soybean flour (22 subjects), Group B= Intervened with germinated black soybean flour (24 subjects), - Values not reported 
Table.7 Effect of dietary intervention on menopausal symptoms of sexual domain

\begin{tabular}{|c|c|c|c|c|}
\hline \multirow[t]{2}{*}{ Symptoms } & \multicolumn{2}{|c|}{ Group A } & \multicolumn{2}{|c|}{ Group B } \\
\hline & Before int. & After int. & Before int. & After int. \\
\hline \multicolumn{5}{|c|}{ Decreased sexual desire (Loss of libido) } \\
\hline Yes & 13.6 & 63.6 & 50 & 50 \\
\hline No & 13.6 & 13.6 & 20.8 & 16.7 \\
\hline No comment & 9.1 & 4.6 & 8.3 & 12.5 \\
\hline Not applicable & 18.2 & 18.2 & 20.8 & 20.8 \\
\hline \multicolumn{5}{|c|}{ Avoiding intimacy with husband } \\
\hline Yes & 40.9 & 31.8 & 29.2 & 37.5 \\
\hline No & 31.8 & 36.4 & 41.7 & 33.3 \\
\hline No comment & 9.1 & 13.6 & 8.3 & 8.3 \\
\hline Not applicable & 18.2 & 18.2 & 20.8 & 20.8 \\
\hline \multicolumn{5}{|c|}{ Satisfaction after sex } \\
\hline Yes & 27.3 & 22.7 & 29.2 & 33.3 \\
\hline No & 45.5 & 31.8 & 41.7 & 29.2 \\
\hline No comment & 9.1 & 27.3 & 8.3 & 16.7 \\
\hline Not applicable & 18.2 & 18.2 & 20.8 & 20.8 \\
\hline
\end{tabular}

Group A= Intervened with raw black soybean flour (22 subjects), Group B= Intervened with germinated black soybean flour (24 subjects), - Values not reported

Fig.1 Study design

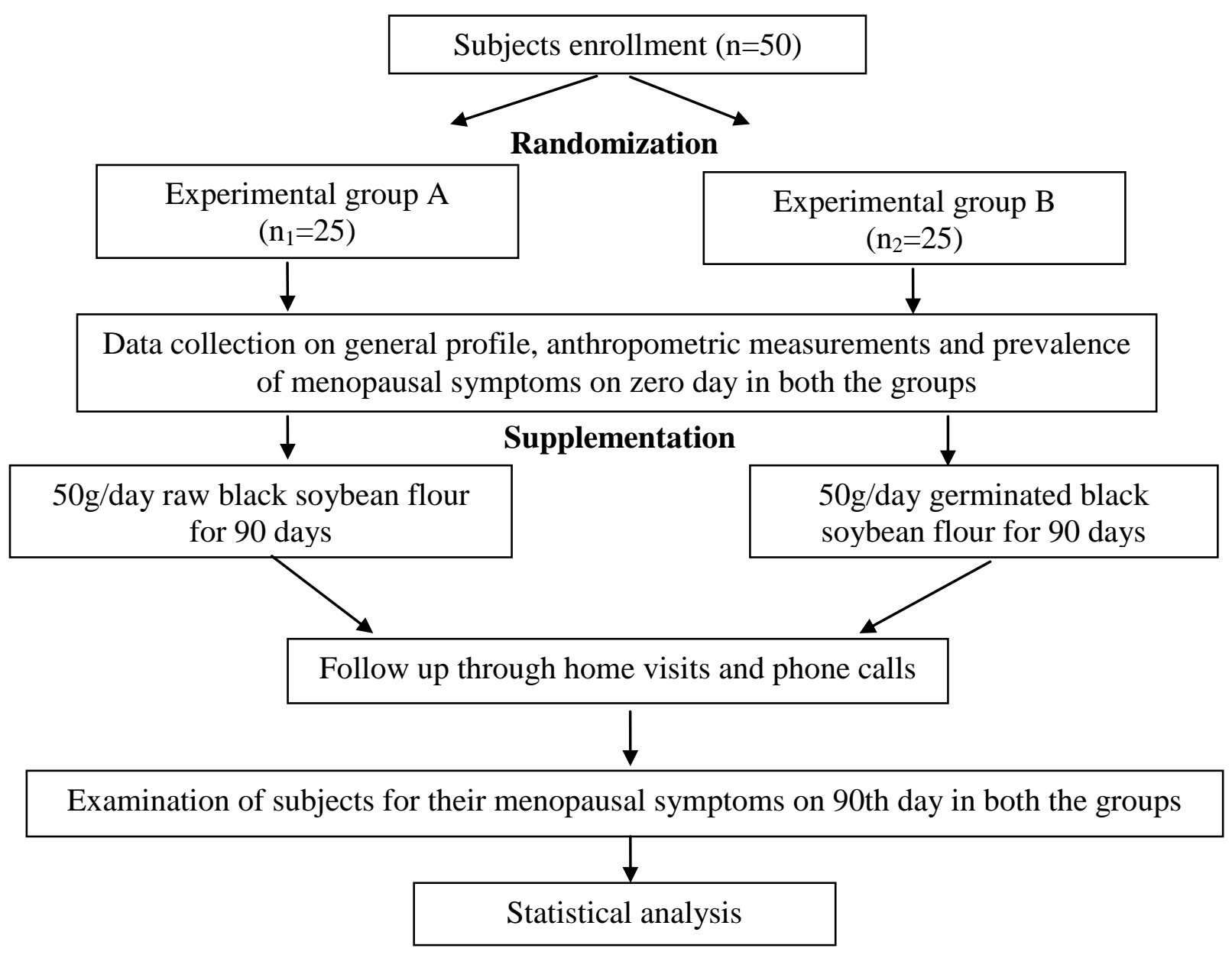


Fig.2 Effect of dietary intervention on vasomotor symptoms of subjects

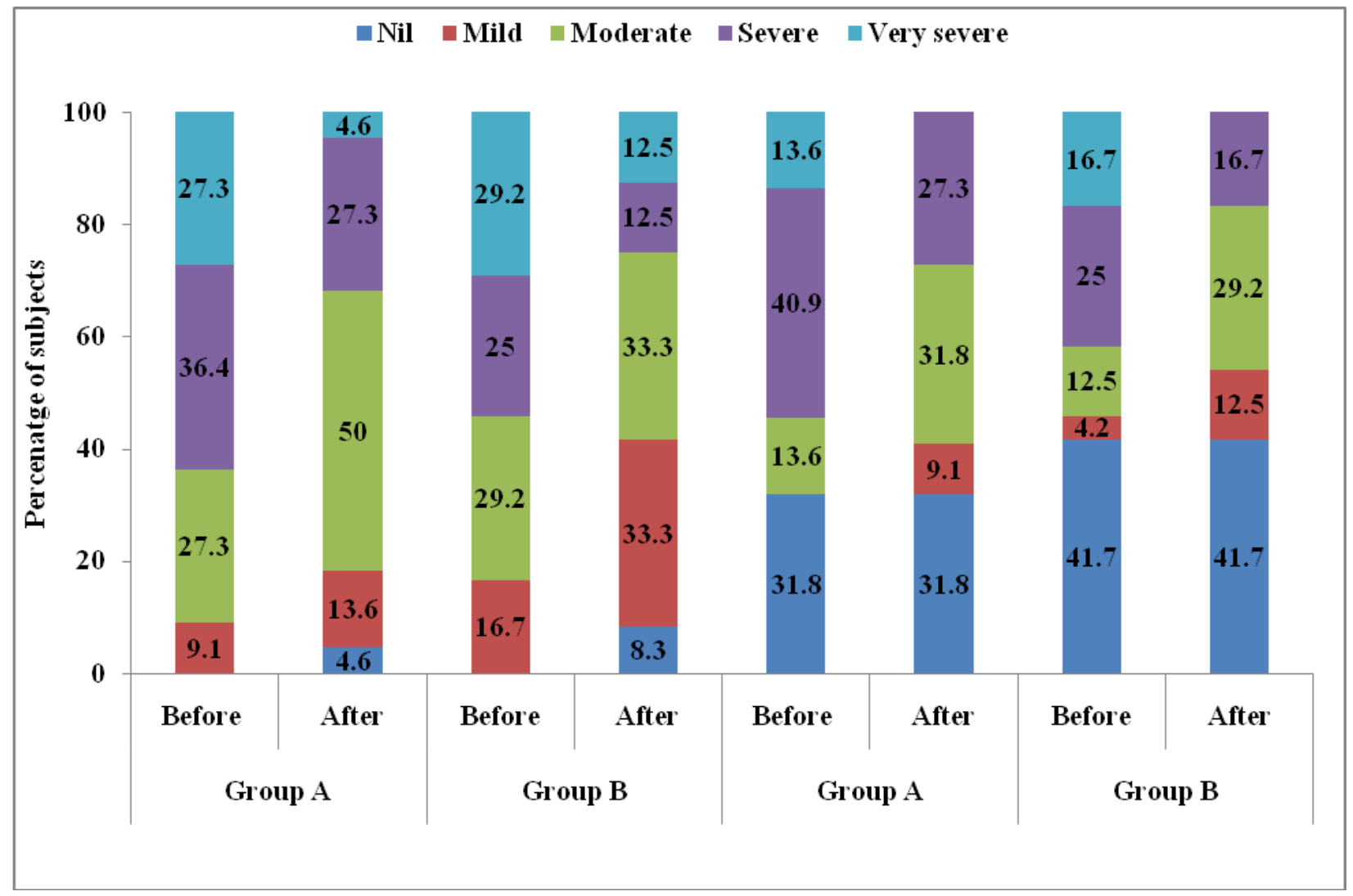

Fig.3 Classification of subjects on the basis of Body Mass Index (BMI)

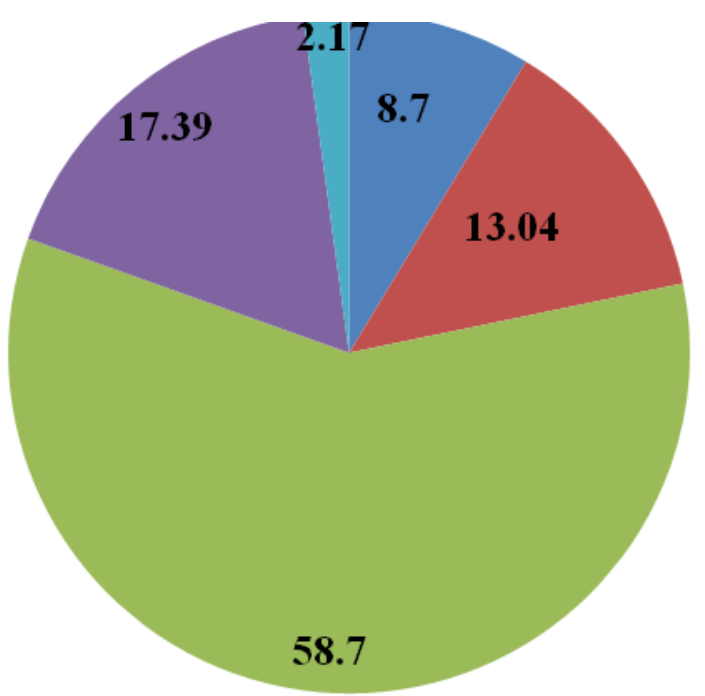

Normal $₫$ Overweight $\square$ Pre-obese $\square$ Obesity Grade I $\square$ Obesity Grade II 
Postmenopausal women have an increased tendency for gaining weight. The reason might be attributed the declining levels of estrogen which leads to change in fat distribution (Rosano et al., 2007) from gynoid to android as well the physical inactivity. Mandal and Chaudhuri (2010) reported significant positive correlation of estrogen levels with breadth and circumference measures of trunk, thigh circumference and with body weight.

A descriptive cross-sectional study conducted by Karmakar et al., (2018) reported lack of energy (93\%), decrease in stamina (88\%), aches in neck or head $(76 \%)$, low backache $(69 \%)$, frequent urination (63\%), drying skin and changes in appearance, texture, tone of skin (40\%) being the most commonly reported physical symptoms. Masjoudi et al., (2017) reported the muscle/joint problem $(82.7 \%)$ being the major problem related to physical domain.

Various studies have reported symptoms under physical domain including joint and muscular pain in the range of 15.90 (Asadi et al., 2012) to $89.50 \%$ (Ahlawat et al., 2016) and physical exhaustion in the range of 29.30 (Gyawali et al., 2016) to 93\% (Goyal et al., 2012). Bladder problems varies from 8.1(Ahlawat et al., 2016) to 63\% (Karmakar et al., 2017) with the common symptoms of frequent urination and bladder inconsistence. The common urogenital symptoms i.e. vaginal dryness/itching and change in sexual desire has been reported in the range of $6.70-41.10 \%$ (Ahlawat et al., 2016; Asadi et al., 2012) and 11.40-49\% (Gyawali et al., 2010; Karmakar et al., 2017), respectively. During premenopausal period, estrogen promotes vaginal colonization by lactobacilli that metabolizing glycogen and producing lactic acid, and maintains intravaginal health by lowering the intravaginal $\mathrm{pH}$ level. A lower vaginal $\mathrm{pH}$ inhibits uropathogen growth, preventing vaginal infections. Decreased estrogen secretion in postmenopausal women depletes lactobacilli and increases intravaginal $\mathrm{pH}$, resulting in increased vaginal colonization by harmful microorganisms (Larsen and Monif, 2001). Lower prevalence of vaginal symptoms in the subjects of present study might also be attributed to their higher consumption of curd and its products like raita, kadhi etc. with a frequency of more than thrice in a week in about $62 \%$ subjects.

Curd is a rich source of lactobacillus and streptococcus bacteria which have been proven to positively affect the vaginal microflora composition by promoting the proliferation of beneficial microorganisms, altering the intravaginal microbiota composition, preventing vaginal infections and its symptoms in postmenopausal women (Kim and Prak, 2017). The findings of the present study are similar to study by Petricevic et al., (2008) who showed the beneficial role of probiotics (lactobacilli, once daily for 2 weeks) in improving the vaginal flora of postmenopausal women.

None of the subjects reported negative change (increase in severity) in any of the symptoms of five domains with the dietary intervention of black soybean flour. The overall improvement in menopausal symptoms of subjects might be attributed to the antioxidant property of the black soybean flour which contains high contents of $\alpha$-tocopherol, isoflavones, flavonoids and anthocyanins, possessing high biological activity (Kumar et al., 2010). Dobhal (2018) reported the antioxidant activity of raw and germinated black soybean flour as 65.52 and $52.77 \%$, respectively, which is higher than the values reported by Malencic et al., (2007) in yellow soybean. This result implies that black soybean intake on regular basis is beneficial in ameliorating the menopausal symptoms with no adverse effects on severity of menopausal symptoms in postmenopausal women. 
The present study investigated the palliative effect of black soybean flour on menopausal symptoms of postmenopausal women. The results indicated that menopausal symptoms under physical, psychological and vasomotor domain showed significant improvement with dietary intervention while symptoms of vaginal health and sexual domains didn't show any significant improvement. None of the subjects reported negative effect of the dietary intervention which implies that black soybean intake on regular basis is beneficial in ameliorating the menopausal symptoms with no adverse effects. Hence, it is recommended to encourage incorporation of black soybean flour in daily diet as it can as improve complications among postmenopausal women and improve their quality of life.

\section{Acknowledgement}

The authors are thankful to participants without whom this study would not have been possible. We acknowledge our deep sense of indebtedness to the G.B. Pant University of Agriculture and Technology, Pantnagar who permitted us to conduct this study.

\section{References}

Abdollahi, A.A., M. Qorbani, H. Asayesh, A. Rezapour, M. Noroozi and M. Mansourian. 2013. The menopausal age and associated factors in Gorgan, Iran. Medical Journal of The Islamic Republic of Iran 27 (2): 50-56.

Abedzadeh, K.M., M. Taebi, Z. Sadat, F. Saberi and Z. Karimian. 2012. Prevalence and severity of menopausal symptoms and related factors among women 40-60 years in Kashan, Iran. Nursing and midwifery studies 1 (2): 88-93.

Ahlawat, P., M. M. Singh, S. Garg and A. Ramalingam. 2016. Prevalence of postmenopausal symptoms, health seeking behaviour and associated factors among postmenopausal women in an urban resettlement colony of Delhi. International Journal of Health Sciences and Research 6 (4): 51-56.

Asadi, M.; Z. Jouyandeh and F. Nayebzadeh. 2012. Prevalence of menopause symptoms among Iranian women. Journal of Family and Reproductive Health 6 (1): 23-30.

Bairy, L., A. Shalini, P. Bhat and R. Bhat. 2009. Prevalence of menopausal symptoms and quality of life after menopause in women from South India. Australian and New Zealand Journal of Obstetrics and Gynaecology 49: 106-109.

Betts, J.G., P. Desaix, E. Johnson, J.E. Johnson, O. Korol, D. Kruse, B. Poe, J.A. Wise, M. Womble and K.A. Young. 2017. Bone tissue and the skeletal system. In: Anatomy and Physiology. OpenStax College, Rice University, Houston, Texas. pp 244.

Chen, Z., J. Wang, W. Liu, and H. Chen. $2017 . \quad$ Physicochemical characterization, antioxidant and anticancer activities of proteins from four legume species. Journal of Food Science and Technology 54(4): 964972.

Darke, G. 1996. Discourses on the Menopause and Female Sexual Identity. In: Holland, J. and L. Adkins (eds) Sex, Sensibility and the Gendered Body. Explorations in Sociology (British Sociological Association conference volume series). Palgrave Macmillan, London.

Dhulkhed, V.K., M.G. Dhorigol, R. Mane, V. Gogate and P. Dhulkhed. 2008. Basic statistical concepts for sample size estimation. Indian Journal of Anaesthesia 52 (6): 788-793.

Dobhal, N. 2018. Nutritional evaluation and processing of black soybean (glycine 
max) for its therapeutic effect in ameliorating lipid profile and menopausal symptoms of hypertensive women. Ph.D. Thesis submitted to G.B. pant University of Agriculture and Technology, Pantnagar. 215 pp.

Dobhal, N. and R.S. Raghuvanshi. 2008. Nutritional profile of women of district Uttarkashi in Uttarakhand. Journal of Eco-friendly Agriculture 3 (2): 194198.

Ganesan, K. and X. Baojun. 2017. A critical review on polyphenols and health benefits of black soybeans. Nutrients 9: 455 (17 pp).

Goodman, N.F., R.H. Cobin, S.B. Ginzburg, L.A. Katz and D.E. Woode. 2011. Menopause Guidelines Revision Task Force. American Association of Clinical Endocrinologists Medical Guidelines for Clinical Practice for the Diagnosis and Treatment of Menopause. Endocrine Practice 17(6).

Goyal, S., U. Malagi, R. Naik and B. Kasturiba. 2012. Menopausal symptoms and nutritional status of perimenopausal women. Karnataka Journal of Agricultural Sciences 25 (4): 506-509.

Green, R., A.J. Polotsky, R.P. Wildman, A.P. McGinn, J. Lin, C. Derby, J. Johnston, K.T. Ram, C.J. Crandall, R. Thurston, E. Gold, G. Weiss and N. Santoro. 2009. Menopausal symptoms within a Hispanic cohort: SWAN, the Study of Women's Health across the Nation. Womens Health (Lond Engl) 5 (2): 127-133.

Griffiths, A., S.J. MacLennan and J. Hassard. 2013. Menopause and work: An electronic survey of employees' attitudes in the UK. Maturitas 76: 155-159.

Gyawali, S., S.N. Subedi, N. Yasmin and S. Pandey. 2016. Health care seeking practice for menopausal problems among women in Syangja District,
Nepal. International Journal of Health Sciences and Research 6 (8): 247-253. Hilditch, J.R. and J. Lewis. 1996. The menopause-specific quality of life questionnaire. Maturitas 24: 161-175.

Hipparagi, Y., R. Singh, D.R. Choudhury and V. Gupta. 2017. Genetic diversity and population structure analysis of Kala bhat (Glycine $\max$ (L.) Merrill) genotypes using SSR markers. Hereditas. 154: 9.

ICMR. 2010. Nutrient requirements and recommended dietary allowances for Indians. A report of the expert group of the ICMR. $334 \mathrm{pp}$.

Jelliffe, D.B. 1966. The assessment of nutritional status of the community. WHO Monogr. Ser. No. 53. Geneva, WHO. 245 pp.

Karmakar, N., S. Majumdar, A. Dasgupta and S. Das. 2017. Quality of life among menopausal women: A communitybased study in a rural area of West Bengal. Journal of Mid-life Health 8: 21-27.

Kim, J.M. and Y.J. Park. 2017. Probiotics in the prevention and treatment of postmenopausal vaginal infections: Review Article. Journal of Menopausal Medicine 23 (3): 139-145.

Ko, K.P. 2014. Isoflavones: Chemistry, analysis, functions and effects on health and cancer. Asian Pacific Journal of Cancer Prevention 15:7001-7010.

Kumar, R., A.S. Nawaz, S.K. Holyachi and V. Rao. 2016. Study of quality of life among peri-menopausal women in a rural field practice area of a medical college in Karnataka. National Journal of Community Medicine 7 (3): 160164.

Kumar, V., A. Rani, A.K. Dixit, D. Pratap and D. Bhatnagar. 2010. A comparative assessment of total phenolic content, ferric reducing-anti-oxidative power, 
free radical-scavenging activity, vitamin $\mathrm{C}$ and isoflavones content in soybean with varying seed coat colour. Food Research International 43: 323328.

Larsen, B. and Monif, G.R.G. 2001. Understanding the bacterial flora of the female genital tract. Clinical Infectious Diseases 32 (4): 69-77.

Lu, J., J. Liu and J. Eden. 2007. The experience of menopausal symptoms by Arabic women in Sydney. Climacteric 10:72-79.

Madhukumar, S., V. Gaikwad and D. Sudeepa. 2012. A community based study on perceptions about menopausal symptoms and quality of life of post menopausal women in Bangalore rural. International Journal of Health Sciences and Research 2 (3): 49-56.

Malencic, D., M. Popovic and J. Miladinovic. 2007. Phenolic content and antioxidant properties of soybean (Glycine max (L.) Merr.) seeds. Molecules 12: 576581.

Mandal, A. and B.D. Chaudhari. 2010. Anthropometric-hormonal correlation: an overview. Journal of Life Sciences 2: 65-71.

Mansour, A., Z. Ahadi, M. Qorbani and S. Hosseini. 2014. Association between dietary intake and seasonal variations in postmenopausal women. Journal of Diabetes \& Metabolic Disorders 13: 52.

Masjoudi, M., M.A. Amjadi and E.K.N. Leyli. 2017. Severity and frequency of menopausal symptoms in middle aged women, Rasht, Iran. Journal of Clinical and Diagnostic Research 11 (8): 17-21.

Meschia, M., F. Pansini, A.B. Modena, D. Aloysio, M. Gambacciani, F. Parazzini, C. Campagnoli, G. Maiocchi and E. Peruzzi. 2000. Determinants of age at menopause in Italy: results from a large cross-sectional study. ICARUS
Study Group. Italian Climacteric Research Group Study. Maturitas 34: 119-125.

Pal, A., D. Hande and S. Khatri. 2013. Assessment of menopausal symptoms in perimenopause and postmenopause women above 40 years in rural area. International Journal of Healthcare and Biomedical Research 1 (3): 166174.

Patel, P.A., P.P. Patel, B. Yagnik, K. Vora, A. Verma, A.D. Patel, S.A. Chiplonkar and A.V. Khadilkar. 2016. Nutritional status assessment of women from different occupations in urban and semi-urban regions of Gujarat. International Journal of Food Sciences and Nutrition 3 (2): 381-384.

Patricia, K., G. Steven, Y. Jinoos, T. Laura, J. Laura, Y. Edward and A.C. Lindsey. 2011. Obesity and its measurement in a community-based sample of women with systemic lupus erythematosus. Arthritis Care Res (Hoboken). 63(2): 261-268.

Petricevic, L., F.M. Unger, H. Viernstein and H. Kiss. 2008. Randomized, doubleblind, placebo-controlled study of oral lactobacilli to improve the vaginal flora of postmenopausal women. European Journal of Obstetrics \& Gynaecology and Reproductive Biology 141: 54-57.

Randhawa, R. and S. Sindhu. 2014. Age at natural menopause and menopausal symptoms among rural women of Amritsar. The international weekly Journal for medicine 7 (24): 48-55.

Rosano, G.M., C. Vitale, G. Marazzi and M. Volterrani. 2007. Menopause and cardiovascular disease: The evidence. Climacteric 10: 19-24.

Salvador, T., C. Brotons, B.P. Pisa, R. Macias, E. Hevia and M.M. Castillejo. 2016. Impact of a soy drink on climacteric symptoms: An open-label, crossover, 
randomized clinical trial. Gynecological Endocrinology 32(6): 477-482.

Sen, S. and R. Verma. 2016. Assessment of nutritional status of urban women of Maharashtra, India. IOSR Journal of Nursing and Health Science (IOSRJNHS) 5 (1): 1-7.

Setchell, K.D. 2001. Soy isoflavones-benefits and risks from nature's selective estrogen receptor modulators (SERMs). Journal of the American College of Nutrition 20 (5): 354S$362 \mathrm{~S}$.

Shah, N.C. 2006. Black soybean: An ignored nutritious and medicinal food crop from the Kumaon region of India. Asian Agri-History 10: 33-42.

Snedecor, G.W. and W.G. Cochran. 1967. Statistical methods. 6th Edition, Ames, Lowa, the Lowa state University.

Stearns, V., L. Ullmer, J.F. Lopez, Y. Smith, C. Isaacs and D. Hayes. 2002. Hot flushes. Lancet. 360(9348): 1851-1861.

WHO. 1981. World Health Organisation Scientific Group, Research on the
Menopause, vol. 670. Geneva, Switzerland: World Health Organisation Technical Report Series. Accessed on April 13, 2018.

WHO. 2004. Appropriate body-mass index for Asian populations and its implications for policy and intervention strategies. Lancet 363(9403): 157-163.

Wu, A.H., M.C. Yu, C.C. Tseng and M.C. Pike. 2008. Epidemiology of soy exposures and breast cancer risk. British Journal of Cancer 98: 9-14.

Zhang, Q., F. Li, Y. Yu, X. Yu, Q. Sheng and X. Zhang. 2009. Differential factors associated with hot flashes in Chinese perimenopausal and postmenopausal women. Maturitas. 63: 94-98.

Zhoua, Y., X. Zhoua, X. Guoa, G. Suna, Z. Li, L. Zheng, H. Yanga, S. Yua, W. Li, L. Zoua and Y. Suna. 2015. Prevalence and risk factors of hypertension among pre and post-menopausal women: A cross-sectional study in a rural area of northeast China. Maturitas 80: 282287.

\section{How to cite this article:}

Neetu Dobhal and Rita Singh Raghuvanshi. 2019. Therapeutic Effect of Black Soybean Flour Intervention on Menopausal Symptoms of Women. Int.J.Curr.Microbiol.App.Sci. 8(11): 22362252. doi: https://doi.org/10.20546/ijcmas.2019.811.261 